\title{
Long-range underwater vocalizations of the crabeater seal (Lobodon carcinophaga)
}

\author{
Holger Klinck, ${ }^{\text {a) }}$ David K. Mellinger, Karolin Klinck, and Julia Hager \\ Cooperative Institute for Marine Resources Studies, Hatfield Marine Science Center, Oregon State \\ University, 2030 Marine Science Drive, Newport, Oregon 97365 \\ Lars Kindermann and Olaf Boebel \\ Alfred Wegener Institute for Polar and Marine Research, Am Alten Hafen 26, 27568 Bremerhaven, \\ Germany
}

(Received 15 December 2009; revised 6 May 2010; accepted 10 May 2010)

\begin{abstract}
This study provides a comprehensive description of the acoustic characteristics of the predominant long-range underwater vocalizations of the crabeater seal, Lobodon carcinophaga, derived from stationary and continuous long-term recordings obtained in the Southern Ocean in 2007. Visual screening of data recorded between 1 October and 15 December 2007 indicates that the principal period of vocal activity of the crabeater seal is the latter part of October and all of November, coinciding with the breeding season of this species. Two call types were identified during this period: the low moan call, which has been described in previous studies and the high moan call, a call type newly described here. Out of 17052 manually extracted crabeater seal calls, high-quality recordings of 152 low moans and 86 high moans with a signal-to-noise ratio exceeding $15 \mathrm{~dB}$ were selected and call-specific acoustic features were determined. While the mean duration of the two call types was comparable ( $\sim 2.5 \mathrm{~s})$, the high moan occurred at notably higher frequencies (1000-4900 $\mathrm{Hz}$ ) than the low moan $(260-2500 \mathrm{~Hz})$. This study provides baseline information necessary to develop automated detection algorithms to facilitate systematic screening of extended data sets for crabeater seal vocalizations. (C) 2010 Acoustical Society of America. [DOI: 10.1121/1.3442362]
\end{abstract}

PACS number(s): 43.80.Ev [WWA]

Pages: $474-479$

\section{INTRODUCTION}

The crabeater seal, an Antarctic pack-ice seal of circumpolar distribution, is the most abundant of all pinniped species worldwide, with a population estimated at 10-15 million (Jefferson et al., 2008), which comprises approximately half of the total world number of pinnipeds (Siniff, 1991). The crabeater seal has been studied within the Antarctic pack-ice seal program (APIS) and is probably the best researched of all the Antarctic pack-ice seals (e.g., Southwell et al., 2008, Southwell et al., 2005, McDonald et al., 2008, Burns et al., 2008). Nevertheless, significant gaps still exist in our knowledge about this species, some of which might now be addressed with long-term passive acoustic monitoring.

To date, only three scientific papers discuss the underwater vocalizations of this species. Stirling and Siniff (1979) describe a single groan-like underwater call type for the crabeater seal recorded near the South Shetland Islands, Antarctica. Their analysis is based on acoustic data recorded from 6 October through 2 November 1976, with a total recording duration of $8 \mathrm{~h}$, and 22 October through 20 November 1977, with a total recording duration of $14 \mathrm{~h}$. Their recordings include only a few occurrences of the "groan like" carbeater seal call, and no detailed analysis of call characteristics was performed at the time. Stirling and Siniff (1979) also recorded an additional call type during the breeding season

\footnotetext{
a) Author to whom correspondence should be addressed. Electronic mail: holger.klinck@oregonstate.edu
}

which might be produced by crabeater seals as well, although further information about the "growl like" call was not given. Thomas and DeMaster (1982) describe the diurnal vocalization pattern of crabeater seals on the Antarctic Peninsula. Data were recorded by deploying a recording system on drifting ice floes between 26 October and 21 November 1979, sampling 7 days within this period by recording 2.5 min each hour, with a total recording duration of $7 \mathrm{~h}$. The study refers to Stirling and Siniff (1979) with regard to the description of the underwater vocalizations recorded and the assignment to crabeater seals.

Recently McCreery and Thomas (2009) presented four new crabeater seal vocalizations which were recorded from a single animal of unknown sex and age at Booth Island (Antarctic Peninsula) during the non-breeding season in February 2007. A total of 18 calls were recorded and analyzed. Based on these findings, McCreery and Thomas (2009) propose that the crabeater seal vocalizations might not be as monotonous as previously assumed. They also emphasize the potential and importance of passive acoustic studies, especially in areas which are difficult for humans to access such as the Antarctic pack-ice.

Here we present detailed analyses of the acoustic features of the low-moan call which has been identified as a crabeater seal call by Stirling and Siniff (1979) and of a new call type (high moan call), which most likely is also produced by crabeater seals during breeding season. The low and high moan call presumably comprise the long-range vocal repertoire of the crabeater seal. These conclusions are 
based on results of temporal and spatial analyses of a continuous long-term data set recorded with an acoustic observatory installed on the Antarctic ice shelf contiguous to the eastern Weddell Sea.

\section{MATERIALS AND METHODS}

This study's acoustic recordings were acquired by the Perennial Acoustic Observatory in the Antarctic Ocean (PALAOA), located at $70^{\circ} 31^{\prime} \mathrm{S}, 8^{\circ} 13^{\prime} \mathrm{W}$ on the Ekström Ice Shelf, approximately $15 \mathrm{~km}$ north of Germany's Neumayer Station. Since December 2005, PALAOA has recorded quasi-continuously the underwater soundscape of the Southern Ocean (Boebel et al., 2006).

Recordings were obtained using RESON TC4032 (sensitivity $-170 \mathrm{~dB}$ re $1 \mathrm{~V} / \mu \mathrm{Pa}$ ) and a RESON TC4033 (sensitivity $-205 \mathrm{~dB}$ re $1 \mathrm{~V} / \mu \mathrm{Pa}$ ) hydrophones, henceforth called hydrophones 1 and 2 respectively, with inter-phone spacing of $300 \mathrm{~m}$. The hydrophones are installed permanently below the $100 \mathrm{~m}$-thick floating ice shelf, $80 \mathrm{~m}$ below the lower shelf boundary and $80 \mathrm{~m}$ above the sea floor (Boebel et al., 2006; Klinck, 2008). The water depth in the vicinity of the observatory is approximately $240 \mathrm{~m}(160 \mathrm{~m}$ water plus $80 \mathrm{~m}$ submerged part of ice shelf), while the ice edge, and hence open water, is approximately $1.5 \mathrm{~km}$ to the North. The stereo signal is amplified by $50 \mathrm{~dB}$ for hydrophone 1 and $80 \mathrm{~dB}$ for hydrophone 2, digitized by a BARIX Instreamer at 16 bit resolution at a sample rate of $48 \mathrm{kHz}$, and transmitted by WLAN as a $192 \mathrm{kbit} / \mathrm{s}$ MP3 stream to the Neumayer Base, where data is stored as a sequence of timestamped MP3 files on hard disk (Kindermann et al., 2008; Klinck, 2008). The effective bandwidth of the recordings is $10 \mathrm{~Hz}$ to $15 \mathrm{kHz}$ and the dynamic range $60-150 \mathrm{~dB}$ re $1 \mu \mathrm{Pa}$.

The recordings revealed a high degree of biotic and abiotic acoustic activity in the Southern Ocean during austral summer, dominated by the vocalizations of Weddell seals, Leptonychotes weddellii, Ross seals, Ommatophoca rossii, crabeater seals, Lobodon carcinophaga, and leopard seals, Hydrurga leptonyx, as well as various cetaceans and icegenerated noise.

The data set analyzed comprises the period 1 October-15 December 2007. Data gaps exist on (1) 21 October 17:00 to 22 October 13:00, (2) 3 November 17:00 to 4 November 15:00, and (3) 23 November 12:00 to 23 November 18:00. The acoustic data were screened visually for crabeater seal calls for 5 consecutive minutes out of every hour, a total of 120 min per day. Data were analyzed using the MATLAB-based spectrogram and measurement package Osprey (Mellinger et al., 2004), using the following spectrogram parameters: frame size and FFT size 4096 samples (0.372 s), overlap 50\% (0.186 s), and Hamming window, for a spectrum filter bandwidth of $23.8 \mathrm{~Hz}$. Further manual screening permitted the identification of a significant number of high-quality low and high moan calls (signal-to-noise ratio $>15 \mathrm{~dB}$ ) for detailed analysis of 5 acoustic features: minimum frequency, maximum frequency, duration, peak frequency, and pulse repetition rate.
The determination of these parameters is based primarily on the "Acoustat" approach of Fristrup and Watkins (1992), which allows extraction of relatively consistent call features at different levels of background noise. Detailed descriptions of this method are given by Fristrup and Watkins (1992), Cortopassi (2006), and especially Mellinger and Bradbury (2007). In brief, a spectrogram is computed and displayed and an analyst places a time/frequency box around the call of interest, the annotation box. This box necessarily includes some of the noise surrounding the call. The measurement system in Osprey then calculates a smaller feature box as follows: energy is summed across frequencies to produce a time envelope of the signal's energy; the continuous span in this envelope that includes the central $90 \%$ of the energy then defines the time bounds of the feature box. The frequency bounds are similarly calculated such that they include $90 \%$ of the signal's energy across frequencies. The upper and lower frequencies of the feature box define the maximum frequency and minimum frequency of the call. The duration is defined as the standard deviation of time, weighted by the energy present at each instant in the time envelope. This calculation results in weighting of the spectrogram cells by the amount of sound energy present, so that the loudest parts of a call have the greatest effect on the parameters. This method causes call features to be relatively insensitive to background noise, as the loudest parts of the calls are least affected by noise. The call's amplitude modulation (AM) rate (in the following called pulse repetition rate, PRR) was extracted from its waveform by applying an envelope technique as described by Klinck et al. (2008).

In a second step, 20 consecutive pairs of high and low moan calls were analyzed in detail to gain information on the distance between potential callers (spatiotemporal correlation). For estimating this the time difference of arrival between the received calls at the two hydrophones as well as the locomotive behavior of crabeater seals had to be taken into account. The call's bearings were estimated by calculating the cross-correlation of each signal as recorded by the spatially separated hydrophones. An example is given in Fig. 1. The cross-correlations (upper part of Fig. 1) and spectrograms (lower part of Fig. 1) for three signals are presented. The cross-correlations are calculated by correlating the data recorded at the second hydrophone with the data recorded at the first one (see Fig. 2). Accordingly, a negative temporal offset of the value of highest correlation value indicates that the signal arrived earlier at hydrophone 2 than hydrophone 1, and vice versa for a positive offset. As an example, the crosscorrelation in the upper left of Fig. 1 indicates that the high moan call (signal 1 in spectrogram) arrived $0.0475 \mathrm{~s}$ earlier at hydrophone 2 than hydrophone 1. For the high moan call shown, the relative direction $\theta$ to the hydrophone array can be calculated as $\theta=\operatorname{acos}\left(\Delta t / t_{\text {ref }}\right)+\theta_{\text {phones, }}$, where $\Delta t$ is the measured time difference of arrival, $t_{\text {ref }}=208 \mathrm{~ms}$ is the straight-line sound travel time between the two hydrophones, and $\theta_{\text {phones }}=315^{\circ}=-45^{\circ}$ is the angle of the line joining the phones relative to North. For the arrival-time difference of $-47.5 \mathrm{~ms}$, the resulting angle is $\theta=58.20^{\circ}$ (see Fig. 2). The result of this calculation is ambiguous, as the time of arrival difference from two hydrophones will result in two possible 


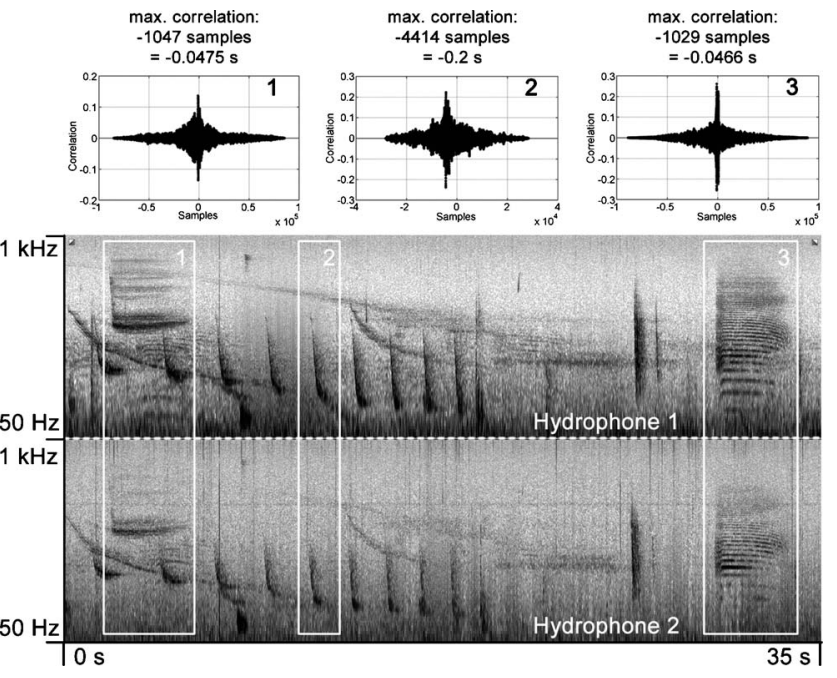

FIG. 1. Example of a cross-correlation analysis of different calls recorded with the PALAOA hydrophones. Signal 1 represents a crabeater seal high moan call, signal 2 represents an element of a Weddell seal chirp call, and signal 3 represents a crabeater seal low moan call. Peaks in the crosscorrelation graphs represent the time of maximum correlation between the signals in the two hydrophones and provide information on the direction of the signal's source (see text).

directions_-in this case either $58.20^{\circ}$ or $211.80^{\circ}$ (see Fig. 2). However, the $211.80^{\circ}$ solution appears unlikely, as this would imply that the vocalizing crabeater seals were located beneath the $100 \mathrm{~m}$ thick ice shelf for an extended period of time. For signals 2 (an element of a Weddell seal chirp call) and 3 (low moan call) in Fig. 1's spectrograms, the corresponding absolute directions are $119.06^{\circ}\left(150.94^{\circ}\right)$ and $57.94^{\circ}\left(212.05^{\circ}\right)$, respectively. These results indicate that the low and high moan call were received from nearly the same direction, while the "chirping" Weddell seal was located in a different direction.

However, there is a slight difference of $0.3^{\circ}$ in the bearings as calculated for the high moan and low moan calls. The

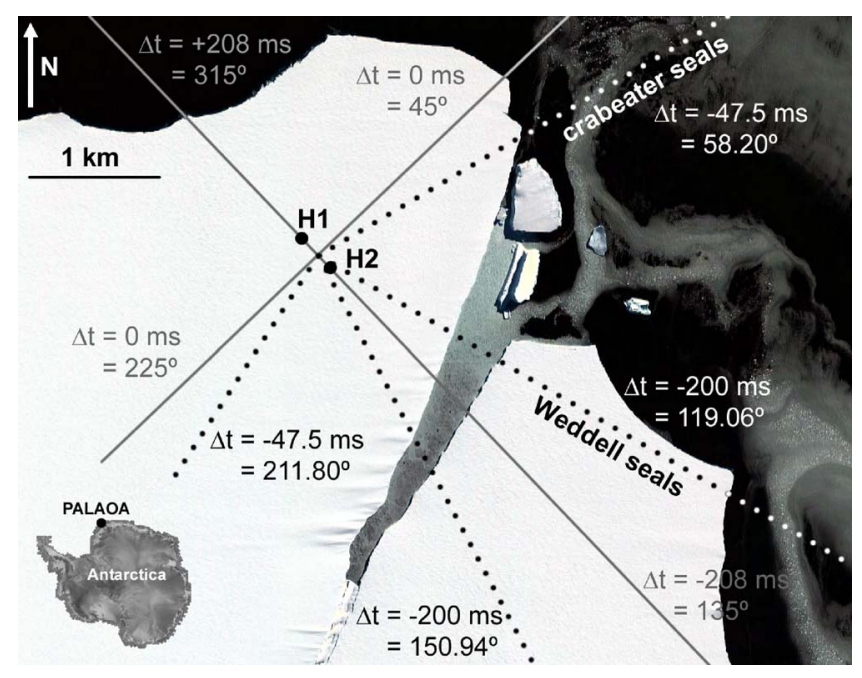

FIG. 2. (Color online) Directions of crabeater seal and Weddell seal calls, as shown in Fig. 1. Because the bearing angles of the two crabeater seal call types differ only slightly, the direction of the crabeater seal call is represented by the bearing angle of the low moan call. Image source: Google Earth-www.earth.google.com. The satellite image was taken 14 March 2006.
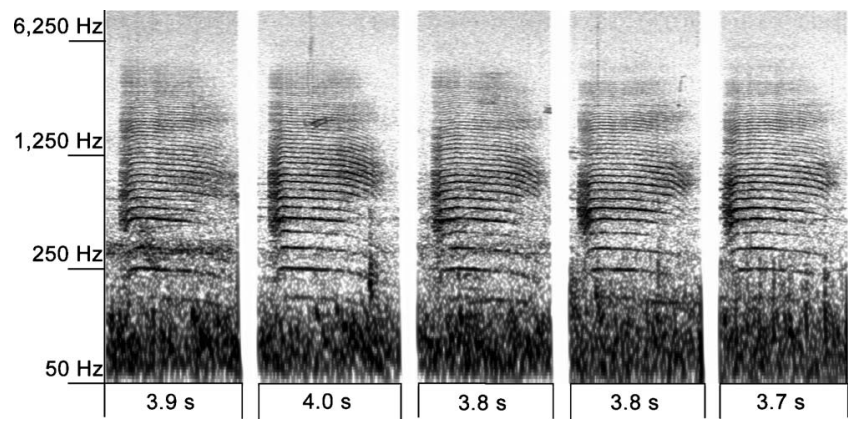

FIG. 3. Spectrogram of five typical low moan calls for crabeater seals. Amplitude modulation in the call results in the series of sidebands apparent here. Spectrogram parameters: frame size and FFT size 4096 samples $(0.372$ s), overlap 50\%, Hamming window, for a spectrum filter bandwidth of 23.8 $\mathrm{Hz}$.

distance $d$ between the acoustic sources can be calculated by $d=2^{*} \cos (\alpha)^{*} b$ with $\alpha=\left(90^{\circ}\right.$-difference in directions $)$ and $b=$ distance between array and animals. The latter may be assumed to span ranges between $1.5 \mathrm{~km}$ and $15 \mathrm{~km}$, which correspond to the distance to the ice shelf edge and the presumed maximum range of high-SNR calls, respectively. In this case $d=15.7 \mathrm{~m}$ to $157.1 \mathrm{~m}$.

In addition, this part of the analysis included a comparison of the received levels (RLs) of all 20 call pairs which provided further information on the distance between potential callers. Finally, the seasonal occurrence of the low and high moan calls was analyzed and compared.

\section{RESULTS}

\section{A. Vocal repertoire}

Our analysis focused on two underwater vocalizations which are most likely produced by crabeater seals. The low moan call type, as rudimentarily described and assigned to crabeater seals by Stirling and Siniff (1979), is "a monosyllabic call, almost like a groan." This call type has also been described as long groan by McCreery and Thomas (2009). In addition, a high moan call type of similar acoustic quality was newly identified in this study's recordings. On the basis of the discussion given below, we deduct that this call type is most likely also produced by crabeater seals.

The number of crabeater seal calls that occurred without any overlapping heterospecific and conspecific vocalizations was limited due to Weddell seal vocalizations, which were omnipresent during the time period analyzed herein. To determine call-specific acoustic characteristics of these two call types, a total of 152 low moans and 86 high moans with a band-limited (low moan: $100 \mathrm{~Hz}-3 \mathrm{kHz}$; high moan: 500 $\mathrm{Hz}-5 \mathrm{kHz}$ ) signal-to-noise ratio (SNR) exceeding $15 \mathrm{~dB}$ were selected from the manually extracted set of 17052 calls. Both call types were characterized by a series of short pulses, i.e., an amplitude modulated tonal signal, which results in a several sidebands in a spectrogram.

\section{B. Low moan call}

The most prominent call type was the low moan call (see Fig. 3). In the visually screened data set, approximately $96 \%$ of the 17052 calls counted were low moans and $4 \%$ 
were high moans. The sideband structure shown in Fig. 3 can, depending on the call's SNR, exceed $10 \mathrm{kHz}$. The PRR (number of pulses per second) decreased at the end of the call, causing the sidebands to converge. The low moan call type often had an arched contour: at the beginning the call frequency increased, then remained constant at the maximum frequency for a period of time, before decreasing again at the end of the call. The duration was $2.5 \pm 0.3 \mathrm{~s}$ (all values are mean $\pm \mathrm{SD}$ ). The energy content of the low moan occurred principally in the frequency range $260-2500 \mathrm{~Hz}$. The peak energy - the frequency with the most energy-was approximately $600 \mathrm{~Hz}$, while the mean pulse repetition rate was $75 \pm 8 \mathrm{~Hz}$ (see Table I).

\section{High moan call}

The high moan (see Fig. 4) started with a brief downsweep followed by a series of short pulses. The PRR was lower than that of the low moan call, with a mean of $50 \pm 8 \mathrm{~Hz}$, but like the low moan, it decreased slightly at the end of the call. Acoustic features of this call type are given in Table II. The mean frequency limits were approximately $1000-4900 \mathrm{~Hz}$, notably higher than the low moan. The mean duration of $2.6 \pm 0.3 \mathrm{~s}$ was comparable to the duration of the low moan.

\section{Spatiotemporal and seasonal correlation between high and low moan calls}

A total of 20 low moan/high moan pairs recorded between 17 October 2007 and 27 November 2007 were analyzed in detail to gain information on the distance between potential callers. Each of the 20 call pairs was selected from different recording days to maximize the likelihood of picking calls from different individuals, groups and distances were used in the analysis. The results showed a mean distance between vocalizing animals of $159 \pm 91 \mathrm{~m}$ (mean $\pm \mathrm{SD}$ ) at a presumed distance of $1500 \mathrm{~m}$, and of $1585 \pm 914 \mathrm{~m}$ at a presumed distance of $15000 \mathrm{~m}$. The time, $\Delta t$, between the received calls of analyzed call pairs varied between $1 \mathrm{~s}$ and $40 \mathrm{~s}$. Taking this into account and the fact that the animals are moving under water, the positions are likely close enough to have been occupied by a single animal. For all analyzed call pairs, the RL of the low moan call was higher than the received level of the high moan call. The absolute difference in received levels $\left(\mathrm{RL}_{\text {low moan }}-\mathrm{RL}_{\text {high moan }}\right)$ for all call pairs was quite similar, $4.28 \mathrm{~dB}+/-2.39 \mathrm{~dB}$, suggesting that the calls were produced by sources in close vicinity of each other.

TABLE I. Principal acoustic features of the low moan call for crabeater seals.

\begin{tabular}{lccccc}
\hline \hline$n=152$ & $\begin{array}{c}\text { Min. freq. } \\
(\mathrm{Hz})\end{array}$ & $\begin{array}{c}\text { Max. freq. } \\
(\mathrm{Hz})\end{array}$ & $\begin{array}{c}\text { Duration } \\
(\mathrm{s})\end{array}$ & $\begin{array}{c}\text { Peak freq. } \\
(\mathrm{Hz})\end{array}$ & $\begin{array}{c}\text { PRR } \\
(\mathrm{Hz})\end{array}$ \\
\hline Mean & 264 & 2520 & 2.5 & 612 & 75 \\
Median & 237 & 2476 & 2.5 & 557 & 74 \\
SD & 89 & 735 & 0.3 & 137 & 8 \\
Min. & 126 & 981 & 1.9 & 316 & 60 \\
Max. & 507 & 4269 & 3.5 & 1008 & 97 \\
\hline \hline
\end{tabular}
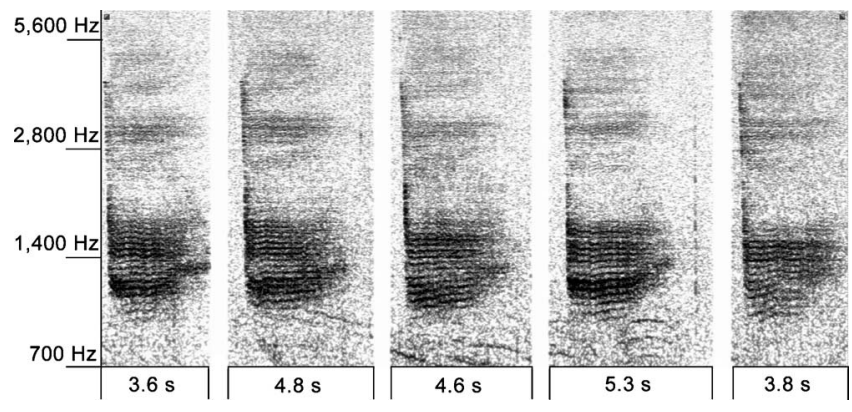

FIG. 4. Spectrograms of five typical high moan calls for crabeater seals. Spectrogram parameters same as in Fig. 3.

Low and high moan calls were visually screened for 5 consecutive minutes out of every hour (minutes 00-04) during the period 1 October to 15 December 2007 to estimate seasonality in calling. The seasonal occurrences of the low and high moan call types are similar: Calling rates increased mid-October, peaked early to mid-November, and decreased in late November and early December (Fig. 5).

The analysis furthermore revealed that in all cases in which a high moan was identified in a 5 min block of data, a low moan was present too. During periods without high moans, early October to mid-December, no low moans were detected either. So low moans were observed often without high moans, but high moans were never observed without low moans.

\section{DISCUSSION}

This study covers two call types that we associate with crabeater seals: the low and high moan. While the low moan has previously been associated with crabeater seals on the basis of concurrent visual observations, the existence and origin of the high moan has not yet been reported. The close spatial and temporal association of high and low moans as discussed above strongly suggests that high moans are produced by crabeater seals.

High moan calls were also identified in crabeater seal recordings provided by Thomas and DeMaster (1982) through the Macaulay Library at Cornell University (http:// animalbehaviorarchive.org, catalog \#120630). While these recordings do contain vocalizations of other seal species as well, these are few and only of very low intensity, indicating that those animals were far away from the recording hydrophone. In contrast, sound intensities of the low and high moan calls are of comparable (high) intensity, indicating that both calls types were produced by the same animal or group

TABLE II. Principal acoustic features of the high moan call for crabeater seals.

\begin{tabular}{lccccc}
\hline \hline$n=86$ & $\begin{array}{c}\text { Min. freq. } \\
(\mathrm{Hz})\end{array}$ & $\begin{array}{c}\text { Max. freq. } \\
(\mathrm{Hz})\end{array}$ & $\begin{array}{c}\text { Duration } \\
(\mathrm{s})\end{array}$ & $\begin{array}{c}\text { Peak freq. } \\
(\mathrm{Hz})\end{array}$ & $\begin{array}{c}\text { PRR } \\
(\mathrm{Hz})\end{array}$ \\
\hline Mean & 998 & 4896 & 2.6 & 1308 & 50 \\
Median & 999 & 4644 & 2.5 & 1312 & 49 \\
SD & 67 & 849 & 0.3 & 124 & 8 \\
Min. & 835 & 2909 & 2.0 & 1096 & 40 \\
Max. & 1298 & 6671 & 3.8 & 1541 & 69 \\
\hline \hline
\end{tabular}



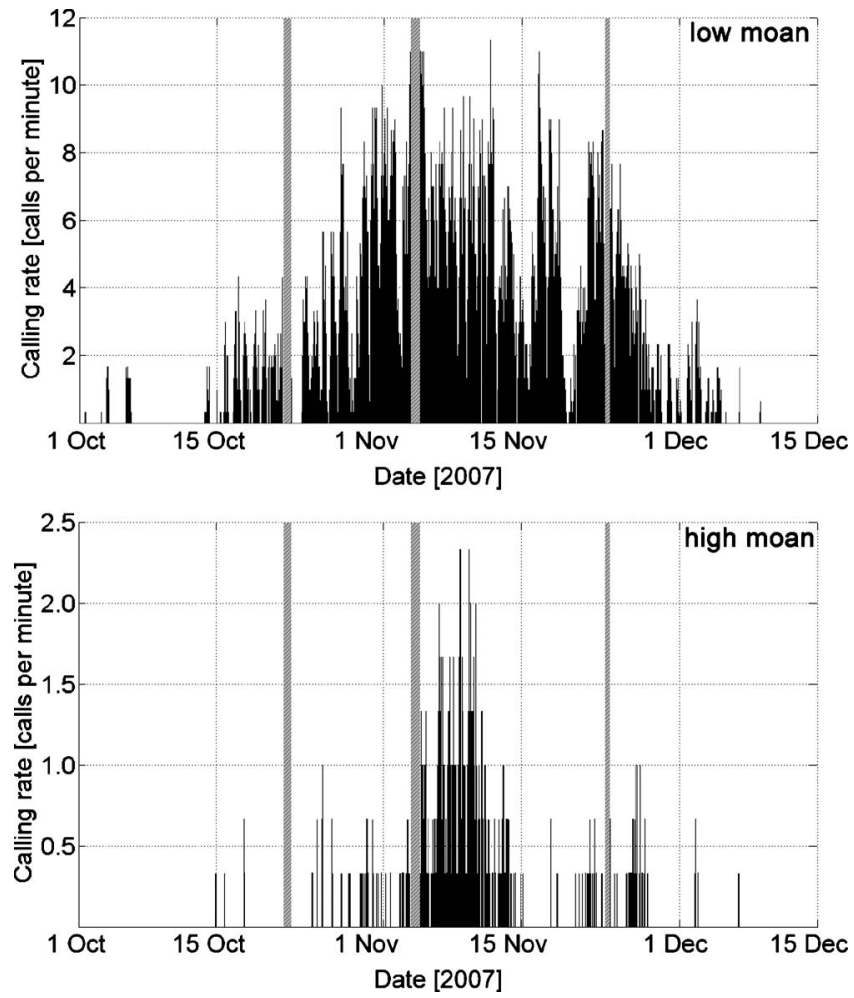

FIG. 5. Seasonal occurrence of the low $(n=16390)$ and high moan $(n$ $=662$ ) for the crabeater seal. Note the difference in $y$-axis scales. Grey bars indicated gaps in data set.

of animals located in the vicinity of the hydrophone. Lastly, Stirling and Siniff (1979) mention that they recorded a call type in addition to the low moan which might be the heredescribed high moan, although no further information about the "growl like" call, as they described it, is given in their publication.

A total of 20 pairs of consecutive high and low moan calls were analyzed in regard to their bearings. The analysis revealed that in all instances the high and low calls were detected by the hydrophones in nearly identical directions, indicating that these sounds were produced by a single animal or group of animals. Younger crabeater seals form large groups when traveling together in the water as an antipredator strategy, and our analysis cannot distinguish multiple calls produced by one individual from calls produced by multiple nearby individuals.

The analysis of the two call types revealed that the seasonal occurrences of the low and high moan call are quite similar, and that in all cases in which a high moan was identified in a 5 min block of data $(n=662)$, a low moan was present too. During periods without low moans, early October to mid-December, no high moans were detected.

Call occurrence during the period 1 October to 15 December 2007 indicates that the period of significant crabeater seal vocal activity in the vicinity of PALAOA is very short: it is basically limited to the period from the end of October and throughout November, which coincides with the breeding season of this species (Southwell et al., 2003). This concordance agrees with the acoustic behavior observed in other ice-breeding seal species, which led to the hypothesis that the calling animals are sexually mature and are principally or entirely males (Rogers and Cato, 2002; Rogers, 2003; Van Parijs, 2003; Rogers, 2007). Male crabeater seals are known to defend a lactating female to maximize the chances of mating when the female enters estrus (Stirling and Siniff, 1979; Shaughnessy and Kerry, 1989; Rogers, 2003). Although the exact timing of the mating season of the crabeater seal is still uncertain, the study by Shaughnessy and Kerry (1989) showed that the ratio of crabeater pups to adults increases rapidly during the 10-day period from 16-25 October, and although pup lactation is unknown, it is inferred from the haul-out behavior of animals with satellite-linked dive recorders to be three weeks (Southwell, 2004). Accordingly the breeding season is likely to take place between end of October and end of November (Southwell et al., 2003), which coincides with the calling behavior found in this study.

The function of the four new call types reported by McCreery and Thomas (2009) during the non-breeding season remains unknown. McCreery and Thomas (2009) mention that the sounds were produced in shallow water when the observed seal was foraging near the rocky bottom. Accordingly the calls could potentially be used for short-range purposes. Short-range vocalizations are not uncommon in Antarctic pack-ice seals. Leopard seals, for example, are known to produce a variety of short-range calls presumably to communicate with conspecifics in close proximity (Rogers et al., 1996). Short-range calls are often associated with lower source levels and are usually not audible in recordings made from greater distances.

Presuming that the low and high moan comprise most of the long-range underwater vocal repertoire of crabeater seals, the question arises as to why their long-range repertoire is rather limited compared to repertoires of other Antarctic seals. Ross seals, for example, are known to produce at least 4 call types (Van Opzeeland et al., 2010) while leopard seals feature 8 principal call types (Rogers et al., 1996; Klinck, 2008) and Weddell seals 30 or more (Thomas and Kuechle, 1982; Pahl et al., 1997). A possible explanation could be the mating strategy of this species. Male crabeater seals maintain strategic positions close to estrous females through direct physical contests with rival males. In this case there is less need for the males to advertise themselves to estrous females, and their communication is less versatile as it is primarily used in male-male interactions (Rogers, 2005; Stirling and Thomas, 2003).

In summary, the study provided valuable information on the long-range underwater vocal repertoire and calling behavior of crabeater seals in the eastern Weddell Sea. The detailed description of the low and high moan call type are essential to allow scientists to develop automated detection algorithms to facilitate systematic screening of extended data sets for crabeater seal vocalizations.

\section{ACKNOWLEDGMENTS}

The authors thank Tracey Rogers, Sharon Nieukirk, Sara Heimlich, and two anonymous reviewers for their helpful comments on earlier versions of the manuscript. Field work and maintenance of PALAOA would not have been possible without the help of the AWI logistics department and the 
Neumayer overwintering teams. The PALAOA project was partly funded by the Bremerhavener Gesellschaft für Innovationsförderung und Stadtentwicklung (BIS) and the European Union. Partial funding also came from Award No. N00244-07-1-0005 from the U.S. Naval Postgraduate School. This is NOAA/PMEL contribution No. 3283.

Boebel, O., Kindermann, L., Klinck, H., Bornemann, H., Plötz, J., Steinhage, D., Riedel, S., and Burkhardt, E. (2006). "Acoustic observatory provides real-time underwater sounds from the Antarctic Ocean," EOS Trans. Am. Geophys. Union 87, pp. 361-366

Burns, J. M., Hindell, M. A., Bradshaw, C. J. A., and Costa, P. D. (2008), "Fine-scale habitat selection of crabeater seals as determined by diving behavior," Deep-Sea Res., Part II 55, 500-514.

Cortopassi, K. A. (2006). "Automated and robust measurement of signal features," Cornell Laboratory Ornithology, http://www.birds.cornell.edu/ $\mathrm{brp} /$ research/algorithm/automated-and-robust-measurement-of-signalfeatures (Last viewed November, 2009).

Fristrup, K. M., and Watkins, W. A. (1992). "Characterizing acoustic features of marine animal sounds," Technical Report No. WHOI-92-04, Woods Hole Oceanographic Institution, Woods Hole.

Jefferson, T. A., Webber, M. A., and Pitman, R. (2008) Marine Mammals of the World: A Comprehensive Guide to Their Identification (Academic Press, London), 592 pages.

Kindermann, L., Boebel, O., Bornemann, H., Burkhardt, E., Klinck, H., van Opzeeland, I., Ploetz, J., and Seibert, A.-M. (2008). "A perennial acoustic observatory in the Antarctic Ocean," in Bundesamt für Naturschutz Skripten 234: Computational bioacoustics for assessing biodiversity: Proceedings of the International Expert Meeting on IT-Based Detection of Bioacoustical Patterns, edited by K.-H. Frommolt, R. Bardelli, and M. Clausen (German Federal Agency for Nature Conservation, Bonn), pp. $15-28$.

Klinck, H. (2008). "Automated passive acoustic detection, localization and identification of leopard seals: From hydro-acoustic technology to leopard seal ecology," Reports on Polar and Marine Research (Alfred Wegener Institute for Polar and Marine Research, Bremerhaven), Vol. 582, p. 154.

Klinck, H., Kindermann, L., and Boebel, O. (2008). "Detection of leopard seal (Hydrurga leptonyx) vocalizations using the envelope-spectrogram technique (tEST) in combination with a hidden Markov model," Can. Acoust. 36, 118-124.

McCreery, L. L., and Thomas, J. A. (2009). "Acoustic analysis of underwater vocalizations of crabeater seals (Lobodon carcinophagus): Not so monotonous," Aquat. Mamm. 35, 490-501.

McDonald, B. I., Crocker, D. E., Burns, J. M., and Costa, D. P. (2008) "Body condition as an index of winter foraging success in crabeater seals (Lobodon carcinophaga)," Deep-Sea Res., Part II 55, 515-522.

Mellinger, D. K., and Bradbury, J. W. (2007). "Acoustic measurements of marine mammal sounds in noisy environments," in Proceedings of the Second International Conference on Underwater Acoustic Measurements: Technologies and Results, Heraklion, Greece, June 25-29, pp. 273-280.

Mellinger, D. K., Stafford, K. M., and Fox, C. G. (2004). "Seasonal occurrence of sperm whale (Physeter macrocephalus) sounds in the Gulf of Alaska, 1999-2001,” Marine Mammal Sci. 20, 48-62.
Pahl, B. C., Terhune, J. M., and Burton, H. R. (1997). "Repertoire and geographic variation in underwater vocalizations of Weddell seals (Leptonychotes weddellii) at the Vestfold Hills, Antarctica," Aust. J. Zool. 45, 171-187.

Rogers, T. L. (2003). "Factors influencing the acoustic behaviour of male phocid seals," Aquat. Mamm. 29, 247-260.

Rogers, T. L. (2005). "Influences of female pupping habitat and maternal care on the vocal repertoire size of male phocid seals," Aquat. Mamm. 31, 96-103.

Rogers, T. L. (2007). "Age-related differences in the acoustic characteristics of male leopard seals, Hydrurga leptonyx," J. Acoust. Soc. Am. 122, 596605 .

Rogers, T. L., and Cato, D. H. (2002). "Individual variation in the acoustic behaviour of the adult male leopard seal, Hydrurga leptonyx," Behaviour 139, 1267-1286.

Rogers, T. L., Cato, D. H., and Bryden, M. M. (1996). "Behavioural significance of underwater vocalisations of leopard seals, Hydrurga leptonyx," Marine Mammal Sci. 12, 414-427.

Shaughnessy, P. D., and Kerry, K. R. (1989). "Crabeater seals Lobodon carcinophagus during the breeding season," Marine Mammal Sci. 5, 6877.

Siniff, D. B. (1991). "An overview of the ecology of Antarctic seals," Am. Zool. 31, 143-149.

Southwell, C. J. (2004). "Satellite-linked dive recorders provide insights into the reproductive strategies of crabeater seals (Lobodon carcinophagus)," J. Zool. 264, 399-402.

Southwell, C. J., Kerry, K. R., and Ensor, P. H. (2005). "Predicting the distribution of crabeater seals Lobodon carcinphaga off East Antarctica during the breeding season," Mar. Ecol.: Prog. Ser. 299, 297-309.

Southwell, C. J., Kerry, K. R., Ensor, P. H., Woehler, E. J., and Rogers, T. L. (2003). "The timing of pupping by pack-ice seals in East Antarctica," Polar Biology 26, 648-652.

Southwell, C. J., Paxton, C. G. M., Borchers, D., Boveng, P., and de la Mare, W. (2008). "Taking account of dependent species in management of the Southern krill fishery: Estimating crabeater seal abundance off East Antarctica," J. Appl. Ecol. 45, 622-631.

Stirling, I., and Siniff, D. B. (1979). "Underwater vocalizations of leopard seals (Hydrurga leptonyx) and crabeater seals (Lobodon carcinophagus) near South Shetland Islands, Antarctica," Can. J. Zool. 57, 1244-1248.

Stirling, I., and Thomas, J. A. (2003). "Relationships between underwater vocalizations and mating systems in phocid seals," Aquat. Mamm. 29, $227-246$

Thomas, J. A., and DeMaster, D. P. (1982). "An acoustic technique for determining diurnal activities in leopard (Hydrurga leptonyx) and crabeater (Lobodon carcinophagus) seal," Can. J. Zool. 60, 2028-2031.

Thomas, J. A., and Kuechle, V. B. (1982). "Quantitative analysis of Weddell seal underwater vocalizations at McMurdo Sound, Antarctica," J. Acoust. Soc. Am. 72, 1730-1738.

Van Opzeeland, I. , Van Parijs, S , Bornemann, H , Frickenhaus, S, Kindermann, L, Klinck, H. , Plötz, J. , and Boebel, O. (2010). "Acoustic ecology of Antarctic pinnipeds," Mar. Ecol. Prog. Ser., (unpublished).

Van Parijs, S. M. (2003). "Aquatic mating in pinnipeds: A review," Aquat. Mamm. 29, 214-226. 